\title{
Spectral Signatures of Leaf Fall Diseases in Hevea Brasiliensis Using a Handheld Spectroradiometer
}

\author{
Hj.Kamaruzaman Jusoff (Corresponding author) \\ Faculty of Forestry, Universiti Putra Malaysia, 43400 Serdang, Selangor, Malaysia \\ Tel: 60-3-8946-7176 E-mail: kamaruz@aeroscan.com.my \\ Hj. Malek Mohd Yusoff \\ Universiti Teknologi MARA, UiTM Arau, 02600 Perlis, Malaysia \\ Tel: 60-4-9868077 E-mail: malek_uitm@yahoo.com \\ Nurul Hidayah Mohd Ali \\ Department of Forest Production, Faculty of Forestry, Universiti Putra Malaysia \\ 43400 UPM, Serdang, Selangor, Malaysia \\ Tel: 60-3-89467176_E-mail: hai_hidayah@yahoo.com
}

\begin{abstract}
Subtle sensitive changes in leaf canopy reflectance of a disease infected trees can be detected by a spectroradiometer. A typical method of detecting tree stress caused by diseases or pest infestations includes the analysis of spectroradiometry. Early detection of forest tree stress would be useful to minimize tree losses especially in a forest plantation area. The main purpose of this study is to develop the spectral library of individual rubber trees being attacked by diseases using a ground-based handheld field spectroradiometer. The specific objective is to identify the spectral signature characteristics of healthy (control) and "unhealthy" or stressed rubber trees due to leaf diseases as causal factors. The spectral reflectance of each infected rubber tree was separated according to the different wavelength and percent reflectance. The spectral signatures of rubber trees being attacked by diseases were characterized by a low reflectance probably due to the low chlorophyll content in the leaves leading to the tree under stress, thus easily separated from the healthy rubber. Results indicated that three groups of infected trees were well separated at the 530 - $650 \mathrm{~nm}$ (visible) wavelength averaging from $0-30$ percent reflectance. The spectral reflectances of rubber trees with leaf disease in visible (VIS) wavelength were not consistently separable. However, the spectral reflectance of leaf diseases can be well separated at the near infrared range region covering from $700-850 \mathrm{~nm}$ wavelength with a $30-80$ percent reflectance for leaf diseases, respectively. The study implies that leaf diseases for rubber trees can only be identified successfully at the NIR range of wavelength from $700-850 \mathrm{~nm}$ with a $20-80$ percent reflectance. The development of such signature library profile of disease affecting rubber trees will certainly assists in the development of an early disease warning system using an airborne hyperspectral imaging system technology being currently developed in UPM's Forest Geospatial Information \& Survey Laboratory, at Lebuh Silikon, Universiti Putra Malaysia, Serdang.
\end{abstract}

Keywords: Spectral signature, Rubber, Near-infrared, Leaf fall disease, Spectroradiometer

\section{Introduction}

In recent years, Malaysia faced a problem of shortage in tropical hardwood supply caused by the wood based industry seeking for alternative raw materials. One of the possibilities in overcoming this problem is to embark on intensive forest plantation program. Rubberwood, the timber from the species Hevea brasiliensis was one of economic value apart from its use as fuel wood. However, it has gained prominence as a source of timber over the last few years. Now, rubberwood with its abundant supply from vast rubber estate has been identified as the possible source of timber for the future (Lim, 1994). The supply of rubberwood in Malaysia is adequate with the total land area of about 1.8 mil. ha with 
approximately 1.65 mil. ha in Peninsular Malaysia (Anon, 1993). About 0.4 million hectares are in the form of estates while the balance 1.2 million hectare are smallholdings (Haron et al., 1990)

Scientific management and technology development of forest plantation needs to increase production and productivity especially to manage and maintain rubberwood plantation in large scale. In needs of a large amount of reliable information that can only be obtained in a time and cost effective way with the help of aerial photographs and other forms of remote sensing. In spite of importance and urgency, relative less progress has been made in recent years in use of air and space-borne imagery of tropical forest vegetation (Lund, 1997).Remote sensing imagery by hyperspectral imaging sensors has many applications in many sectors such as land-use and cover, agriculture and forestry. For example, foresters use remote sensing for preparing forest cover maps, locating possible access roads and measuring quantities of tree harvest. In this study, specialized photography using color infrared film has been used to detect diseases and insect damage of trees in rubber plantation.

In this study, spectral library were measured for stressed rubber trees compared to healthy rubber tree as a control. Development of spectral library for rubber tree diseases is needed in ways to identify spread of diseases especially in large area of rubber plantation. This data of spectral library can be used for environment application, monitoring vegetation cover and its health and providing a rapid overview of large areas. When we applied to large areas, the cost is low to field checking and monitoring on the ground. The main purpose on this study is therefore to develop spectral library of rubber tree to determine stress/ diseases using a handheld spectroradiometer. Its need because using airborne sensing in management and mapping rubber trees is more valuable and reduces cost in large area plantation. The specific objectives are two-folds namely to determine the suitable wavelength range in the identification of rubber tree leaf diseases in a wild rubber plantation, and to identify the spectral signature characteristics of healthy and unhealthy rubber trees.

\section{Metarials and methods}

\subsection{Instrumentation}

A handheld spectroradiometer (Figure 1) was used to obtain the spectral reflectance of tree selected. In this study, the handheld spectroradiometer that was used for field data collection is the FR (Full Range) Field Spec Spectroradiometer manufactured by Analytical Spectral Devices, Incorporated. Fiber optics is used as alight collectors and cover the ranges from $400 \mathrm{~nm}-750 \mathrm{~nm}$. The light is then projected from the fiber optics onto a holographic diffraction grafting where the different wavelength components were are separated and reflected for collection by the three different detectors. The visible or Near Infrared (VNIR) portion of the spectrum (400 nm - 750 nm) was measured and utilized in this study. The detectors convert the incoming photons into electrons that are stored or integrated until the detectors reading is finished. This photoelectric current for each detector then converted to a voltage, which is in turn digitized by 16 bit analogue to digital converter. The digital data was then transferred to the controlling computer resting on top of the actual radiometer.

\section{$<<$ Insert Figure 1 $>>$}

Integrating sphere with the fiber optic illuminated measure both spectral reflectance and transmittance. It includes a 0.4 inch aperture sample port, an internal baffle and a reference port for a second spectrometer reference. Meanwhile, the leaf adapter is designed for interacting with a leaf sample. It measured spectral absorbance, reflectance and transmittance leaf sample. Leaf adapter is build-in Tungsten/Halogen light source. No fiber optic cable is needed. A handheld Global Positioning System (GPS) was used to locate the precise positioning of the diseased affected rubber trees and also the healthy trees as the control.

\section{Methods}

Figure 2 showed the flow chart of the methodology developed in this study. The first step is setting the objectives of study. Before the data collection, rubber trees were infected by diseases was tagged. The second one is data capture. Firstly, GPS reading of infected rubber trees tagged was collected. GPS points were taken in the study area using a Garmin GPS 12 XL. Point data were taken to locate all trees position that was noted in geographic co-ordinates such as latitude/longitude in degree, minutes and second. In this step, data and information of infected trees were gathered a handheld spectroradiometer. The spectral data was taken on the surfaces of the leaves at the canopy level. During data collecting care was also taken to only sample sunlight portions as to avoid the inclusion of too many shadows in the samples. The data were only collected between $1000 \mathrm{H}$ to $1500 \mathrm{H}$ in daylight time to ensure high enough sun angles resulting adequate lighting of each samples. The reflectance samples that were taken from the surfaces of the leaves should be $0.10 \mathrm{~m}$ from the fiber optic sensor (Mohd Norisham, 2003). This step also includes on the determination of the disease will affect rubber trees on the field. 
The third step was the data analysis. The data that were collected in the field was analyzed using hardware and software. The hardware including personal computer, notebook, printer and handheld spectroradiometer tools such as integrating sphere consist of fiber optic cable, pistol grip and leaf adapter. The software, Ocean Optic measured the amount of light at each wavelength in the sample and was used to transform the digital information. The reflectance curve that was obtained from the Ocean Optic Program was stored in the Excel format to show the differences reflectance curves and help organized the data that were taken from the spectroradiometer.

\section{Results and discussion}

\subsection{Spectral reflectance of rubber trees (leaf diseases) in the visible wavelength (500 - $700 \mathrm{~nm})$}

According to Figure 3, the reflectance curves of affected rubber trees caused by leaf diseases were distinctly separable in the wavelength range between 530 to $650 \mathrm{~nm}$. The highest spectral reflectance in wavelength range between 530 $650 \mathrm{~nm}$ was from the healthy rubber tree 2 that has a percent reflectance range between $10-25$ percent (Figure 3 ). This is probably due to the fact that the healthy rubber tree 2 leaves have higher chlorophyll concentration that resulted in the increased reflectance. Meanwhile, in the wavelength range between $530-650 \mathrm{~nm}$, the lowest spectral reflectance was the affected tree caused by Corynespora Leaf fall Disease with a $-5-10$ percent reflectance (Figure 3a). Other research has documented how chlorophyll affects spectral reflectance. Carter (1993) explained that the low chlorophyll content in the leaves or a change in the composition of secondary light-absorbing pigments leading to the less overall absorption and suitable change in the reflectance spectrum which is linked to reflectance spectral with pigment composition and environmental condition. In the same wavelength range $530-650 \mathrm{~nm}$, Fussicocum Leaf Fall Disease has the highest spectral reflectance of amongst the leaves diseases. This can be also explained by the highest chlorophyll content amongst leaf diseases which results in significantly increased reflectance (Kamaruzaman and Malek, 2007).

\section{$<<$ Insert figure 3 and figure $3 a>>$}

\subsection{Spectral Reflectance of Rubber Trees (Leaf Diseases) in the Near Infrared (NIR) region (700 - $850 \mathrm{~nm})$}

The reflectance curves of affected rubber trees caused by leaf diseases were distinctly separable in reflectance range between $730-800 \mathrm{~nm}$ (Figure 4). The highest spectral reflectance in the wavelength range between $730-800 \mathrm{~nm}$ was the rubber tree affected by Fussicocum Leaf Fall Disease with 55 to 80 percent reflectance (Figure 4a). Nevertheless, in $55-75$ percent reflectance range, healthy tree 2 was identified in the wavelength range between $730-800 \mathrm{~nm}$. There is also a possibility that the rubber tree affected by Fussicocum Leaf Fall Disease is having some form of stress where the leaves seemed to have some symptoms of stress which resulted in a decreased absorption and increased reflectance.

The lowest spectral reflectance in wavelength range between 730 - $800 \mathrm{~nm}$ was Corynespora Leaf Fall Diseases which is the spectral reflectance range between 20 to 40 percent. The other stressed trees due to Leaf Fall Diseases such as Oidium and Collectotrichum (Figs. 5a and 5b) were also characterized by a low spectral reflectance value. Similar results have been reported by Aldakheel and Danson (1997) where they hypothesized that increases in near infrared reflectance in response to foliage decision are related to changes in leaf structure at the cellular level.

\section{$<<$ Insert figure 4, figure $4 \mathrm{a}$ and $5 \mathrm{a}>>$}

\section{Conclusions}

The spectral reflectance curves of rubber tree (leaves diseases) can be best separated at the near infrared range covering from 700 - $850 \mathrm{~nm}$ wavelengths with a reflectance 30 - 80 percent. The rubber trees with leaf diseases have low spectral reflectance probably due to their low chlorophyll content in the leaves leading to the tree under stress and can be easily separated from the healthy trees. It is recommended that future studies should be conducted to map the leaf diseases of rubber plantation in Lebuh Silikon, UPM using airborne hyperspectral sensing.

\section{Acknowledgement}

The authors would like to thank the staff of Aeroscan Precision Sdn. Bhd. for assessing field data and the spectral signatures of the Leaf Fall Diseases of the rubber trees found in the wild rubber plantations in UPM's Lebuh Silikon.

\section{References}

Aldakheel, Y Y., and Danson, F. M. (1997). Spectral reflectance of dehydrating leaves: measurements and modelling. International Journal of Remote Sensing 18, 3683.3690.

Anon. (1993). Rubberwood. A Study of World Supply Potential. A Report Prepared by INDUFOR Oy Helsinki for International Trade Centre, UNTAD/GATT

Carter, G.A. (1993). Responses of Leaf Spectral Reflectance to Plant Stress. Science and Technology Laboratory, National Aeronautics and Space Administration, Stennis Space Center, Mississipi. Botany 80 (3): 239-243.

Haron, N.H., Ahmad, I.A., Seman, A.S.M. (1990). Availability of Rubberwood in Peninsular Malaysia. Proceeding International Rubberwood Seminar. Ed. Hong L.T. et al, FRIM, Kuala Lumpur. Pp 55-69 
Kamaruzaman Jusoff and Malek Hj. Mohd Yusoff. (2007). Identification of Leaf Fall Diseases affecting Hevea brasilliensis using a HandHeld Spectroradiometer. Paper Presented at the 2007 Conference on Plantation Commodities "Visionary Agriculture: Malaysian Commodity Crops in 100 Years", 2-4 $4^{\text {th }}$ July, 2007. Putra World Trade Center, Kuala Lumpur, Malaysia. 9p.

Lund, H.G. (1997). Forestry. Manual of Photographic Interpretation. Second Edition. American Society of Photogrammetry and Remote Sensing,pp. 399-440

Mohd Norisham Mahmood. (2003). Spectral reflectance of 15 Tree Species at Universiti Putra Malaysia's Arboretum, Serdang, Selangor. Unpubl. B.s.(For) Project Report, Faculty of Forestry, Universiti Putra Malaysia, Serdang, Selangor, $61 \mathrm{pp}$.

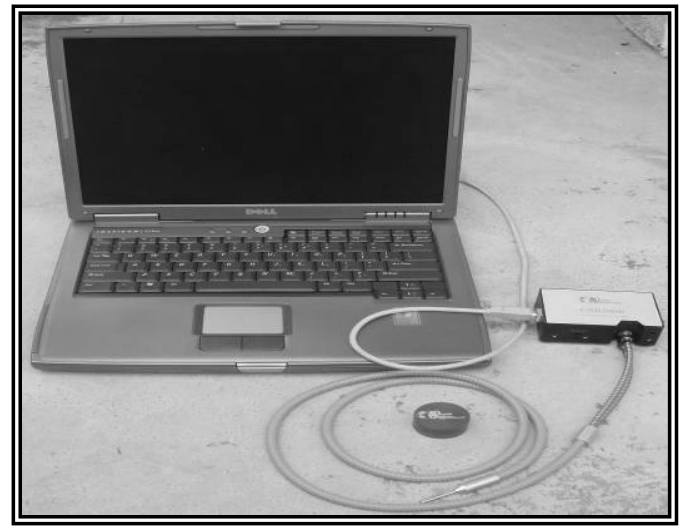

Figure 1. The handheld spectroradiometer complete with the integrating sphere and the leaf adapter

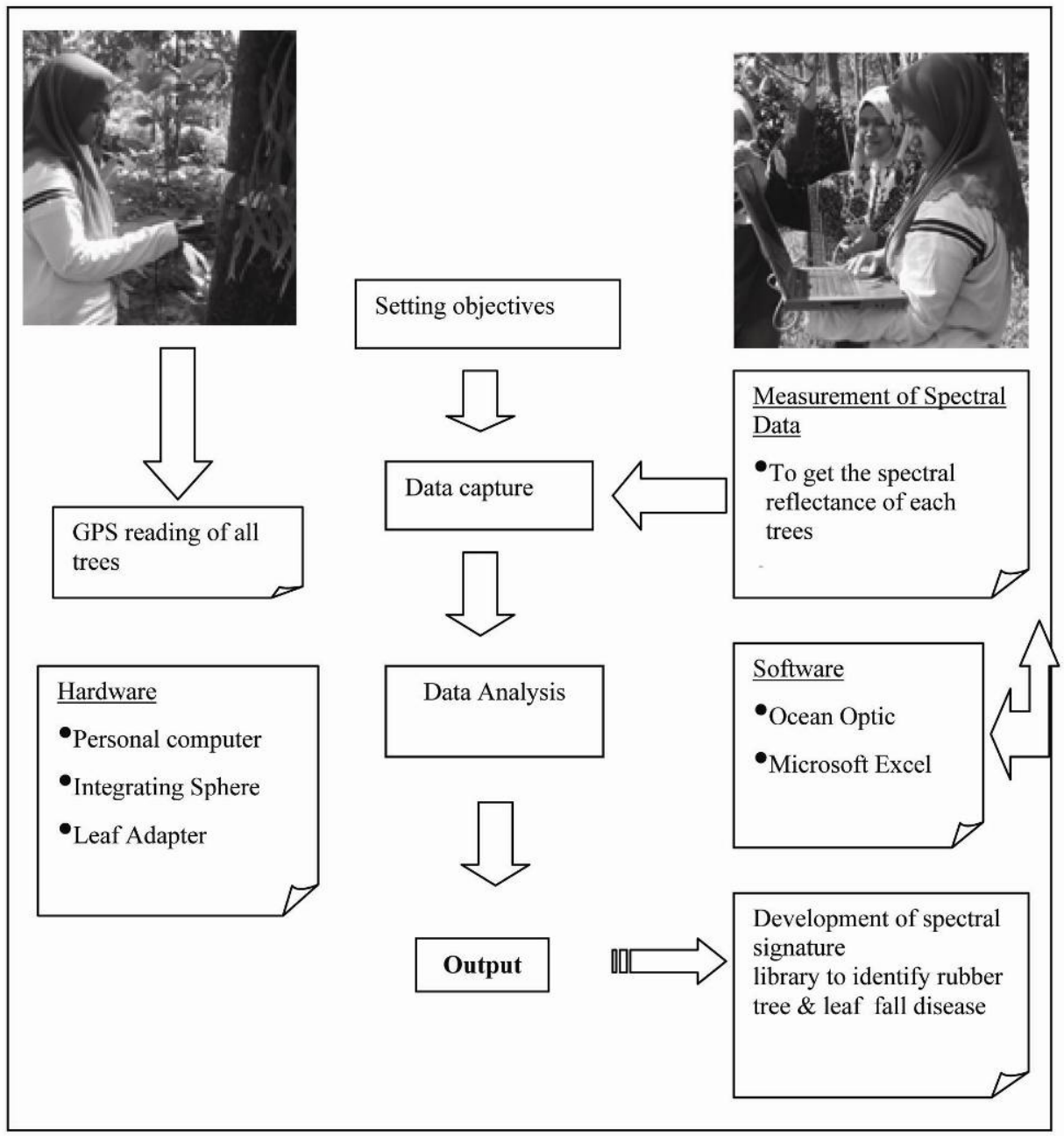

Figure 2. Flowchart of the Methodology 


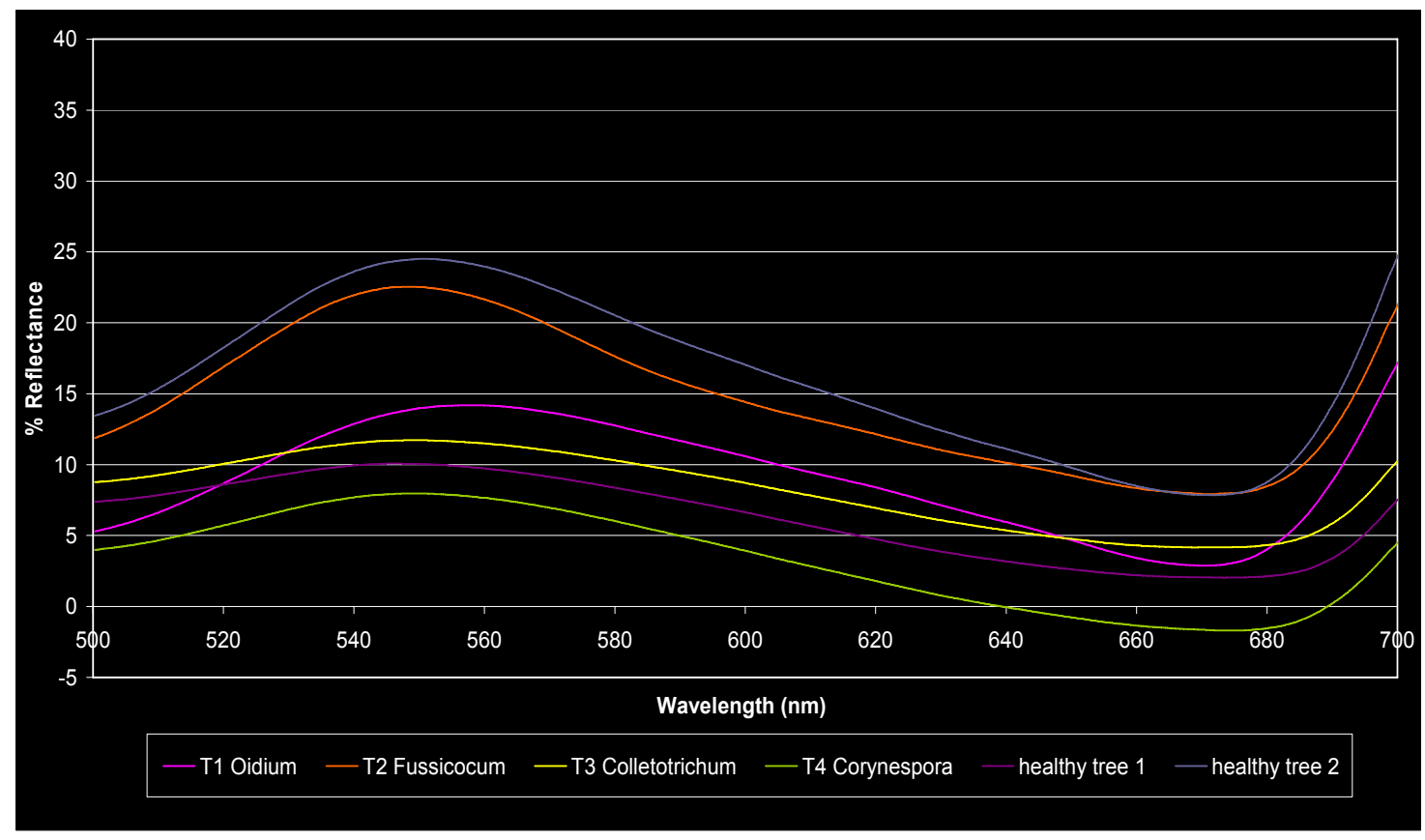

Figure 3. Spectral Reflectance of Rubber Trees (Leaf Fall Diseases) in the Visible Wavelength $(500-700 \mathrm{~nm})$

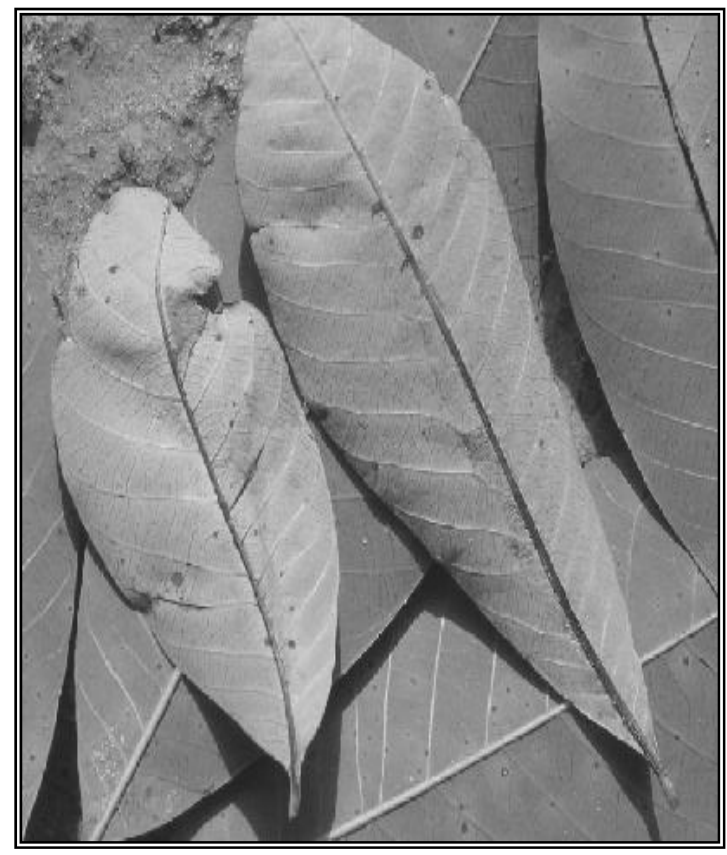

Figure 3a. Corynespora Leaf Fall Diseases 


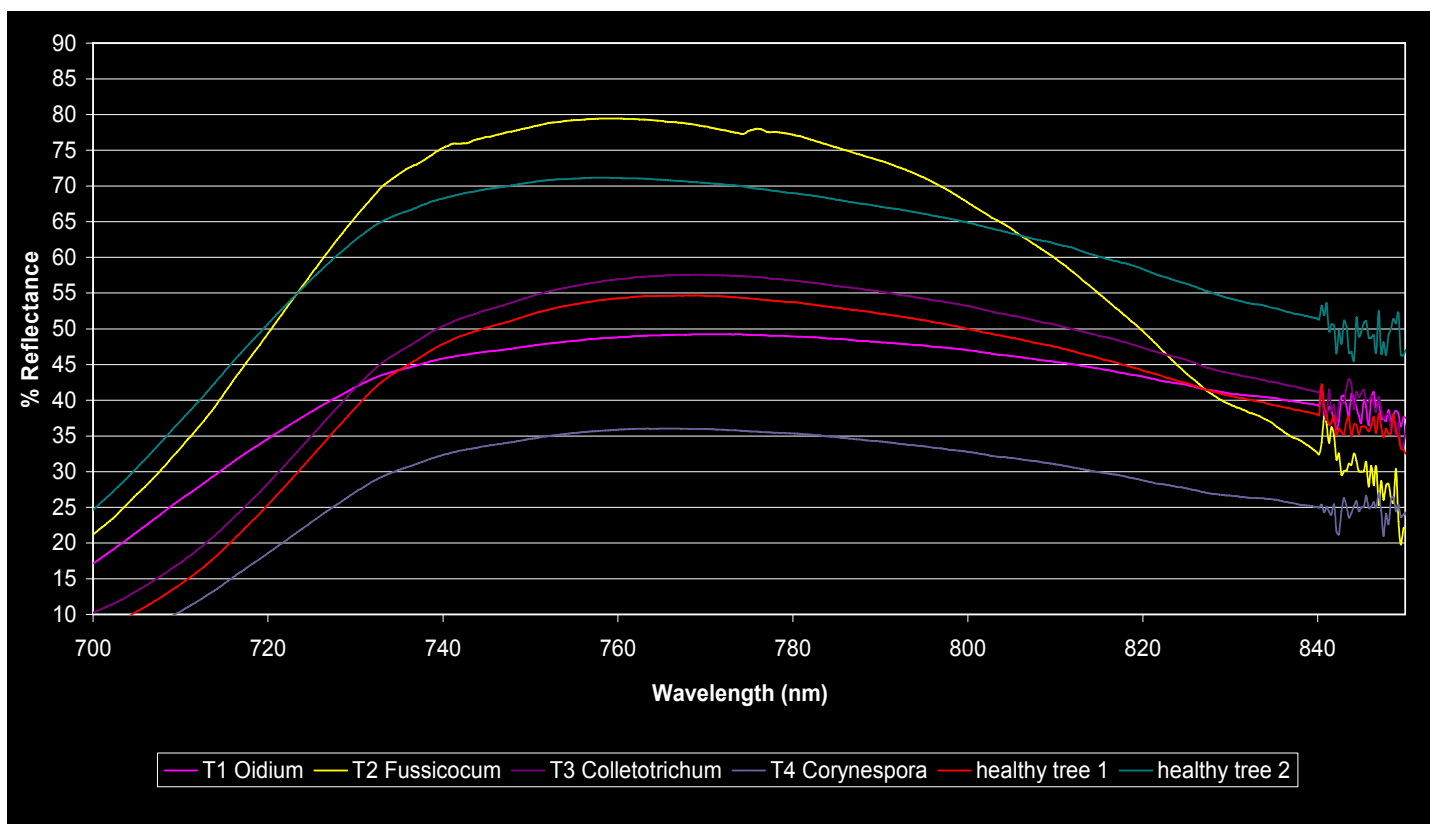

Figure 4. Spectral Reflectance of Rubber Trees (Leaf Diseases) in the Near Infrared (NIR) region (700 - $850 \mathrm{~nm})$

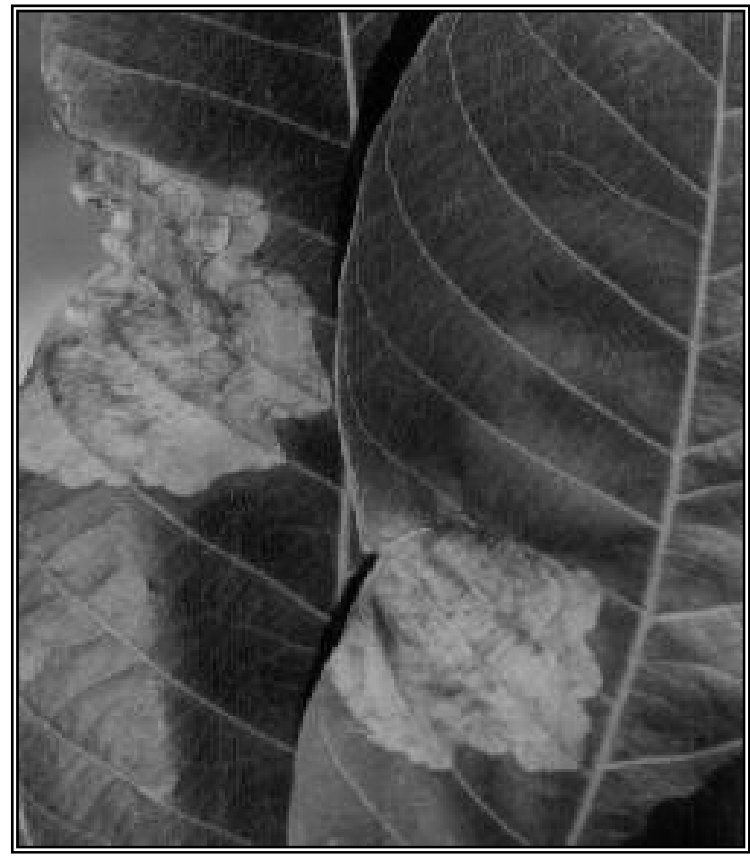

Figure 4a. Fussicocum Leaf Fall Diseases 


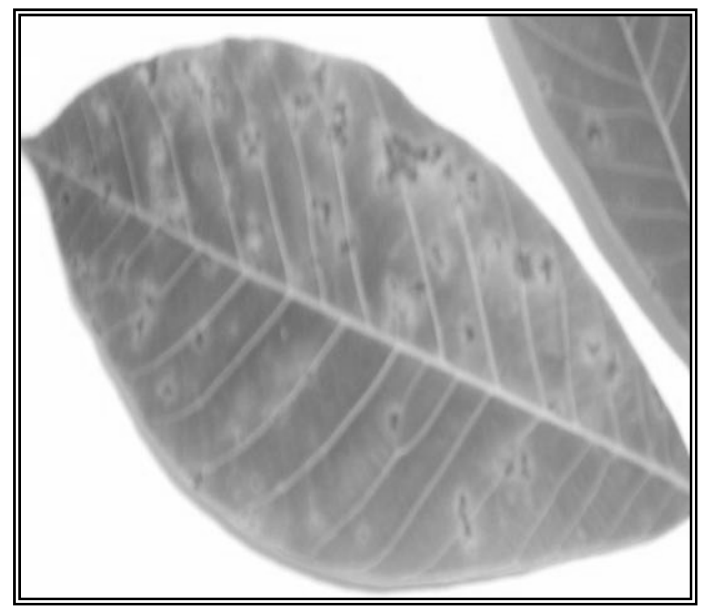

Figure 5a. Oidium Leaf Fall Diseases

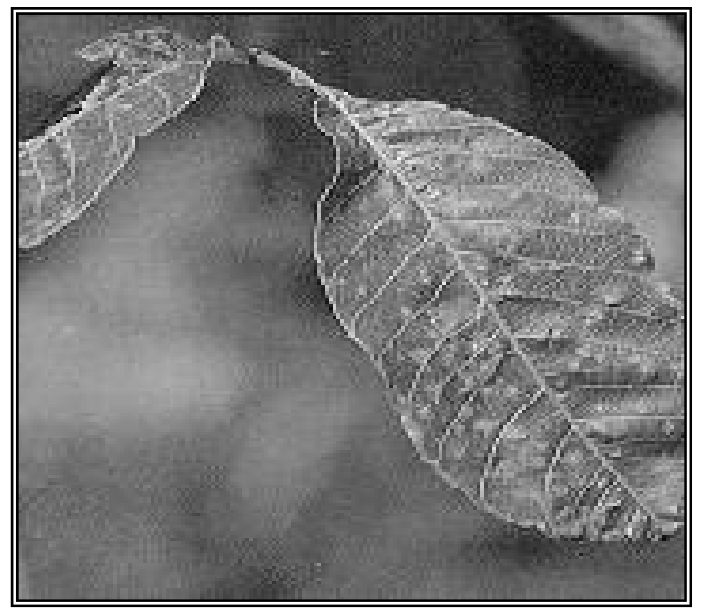

Figure 5b. Colletotrichum Leaf Fall Diseases 